\title{
Assessment of medication adherence using medication adherence rating scale-5 in patients with major non-communicable diseases at tertiary care hospital
}

\author{
Marina Andavar*, Mahalakshmi Natarajan, Mahendravarman Paneer Selvam
}

Department of Pharmacy, Annamalai University, Chidambaram, Tamil Nadu, India

\author{
Received: 15 July 2020 \\ Revised: 07 August 2020 \\ Accepted: 10 August 2020

\section{*Correspondence:} \\ Dr. Marina Andavar, \\ Email: marindrushilapharmd@gmail.com
}

Copyright: (C) the author(s), publisher and licensee Medip Academy. This is an open-access article distributed under the terms of the Creative Commons Attribution Non-Commercial License, which permits unrestricted non-commercial use, distribution, and reproduction in any medium, provided the original work is properly cited.

\begin{abstract}
Background: To assess the medication adherence using medication adherence rating scale (MARS-5) for achieving good clinical outcomes in patients with major non-communicable chronic diseases who are undergoing long-term therapy and to compare the adherence between adult and geriatric patients based on patient counselling.

Methods: A Prospective observational study was conducted in the Department of Medicine, Raja Muthiah Medical College Hospital (RMMCH), Chidambaram, India over a period of 6 months. Patient details were collected using self-designed patient proforma. Patients' medication adherence was assessed using MARS-5 and patients were counselled regarding drug use with the help of pictograms and daily monitoring sheet.

Results: A total of 150 patients were enrolled in the study out of which 77 were adults and 73 were from the geriatric population. $65.33 \%$ were affected with comorbid conditions. Non-compliance was mainly due to forgetfulness, lack of assistance in the elderly population, polypharmacy and also due to failing to refill prescriptions. Nearly half of the population about $40 \%$ showed poor adherence before patient counselling and was reduced to $13.33 \%$ after proper patient counselling. And the medication adherence was found to be more among the adults $90.90 \%$ when compared to the geriatric population $82.19 \%$.

Conclusions: A new approach through pharmaceutical care was implemented; it mainly aims in delivering information regarding the importance of therapy in non-communicable chronic illness and also on the non-therapeutic considerations. It also focuses in conveying the importance of their lives to their families and to the society, thereby improving the adherence to medicine.
\end{abstract}

Keywords: MARS-5, Non-communicable chronic illness, Non-compliance, Pharmaceutical care, Patient counselling

\section{INTRODUCTION}

Adherence to medication is indispensable in the case of chronic illness were the patient has to stick to the prescribed medication for a long period of time whereas adherence in infectious diseases is relatively flexible were the duration of the treatment is less. In the rural setup, adherence has become complicated with the lack of understanding about the health condition or the vital importance of medicine in curing the illness. Nonadherence among the elderly is mainly due to forgetfulness or lack of assistance especially in taking them to the hospital or in delivering the medications at home. Sometimes the elderly due to their inability to read or due to their poor eyesight take the wrong medications at the wrong time or due to lack of knowledge take more medicines. ${ }^{1}$

It is also due to the fact that some of them don't refill the prescriptions or take the medications as prescribed for the recommended period of time. ${ }^{2}$ Some of the working middle age adults do not prioritise coming for regular 
check-up, thus skipping to refill the prescriptions once the medicines get over. Re-filling of prescription is important in the case of diabetes were the set of medicines are changed after monitoring and reviewing of blood glucose level. ${ }^{2}$ Other predictors of non-adherence according to the WHO are co-morbidity, polypharmacy, non-adherence due to adverse effects of the medicine and patients with asymptomatic disease, who do not experience any symptoms from their health condition are susceptible to non-adherence and on the other hand patients with symptomatic disease stick more to symptom relieving medicines than to preventive medicines like the use of analgesics such as NSAIDS, opioids for temporary relief. Increase in frequency of daily doses of medicine increases non-adherence.

Patients' understanding of directions given such as use of insulin pen and inhalers also affect adherence. ${ }^{3}$ Therefore, a new approach has been implemented through Pharmaceutical care by counselling the patients in different areas which includes the importance of using medicines in chronic illness; lifestyle changes like dietary modifications ,exercise; maintenance of hygiene, selfmonitoring. ${ }^{4}$ And it also focuses in encouraging the patients on the importance of their lives to their families and to the society. By effectuating this approach, we can strengthen them in their mental thinking towards the way they look at their own lives and towards adherence to medicine and treatment, thereby reducing hospital readmissions and the burden of health care costs. ${ }^{5}$

\section{METHODS}

\section{Study design, site and period}

A prospective observational study was conducted in the Department of Medicine, Rajah Muthiah Medical College
Hospital (RMMCH), Chidambaram, India over a period of 6 months (November 2018 to April 2019) to assess the medication adherence in patients with major noncommunicable diseases.

\section{Study recruitment procedure}

A total of 150 patients were enrolled in the study. Patients with major non-communicable illness aged more than 18 years were included in the study and patients below 18 years of age, patients with psychiatric illness, chronic infectious diseases, pregnant and lactating women and patients not willing or not providing Informed consent form were not included in the study.

\section{Data collection}

Patient details like demographic characteristics, disease related and therapy related information were recorded using self-designed patient proforma. Patient's drug taking frequency were recorded using daily monitoring sheet and patients were educated regarding drug use and mode of aadministration through pictograms. The medication adherence was assessed by using MARS-5. ${ }^{6}$ Table 1 represents the MARS scale which consists of five items. Scoring for each item is based on the frequency of positive response, for always, often, sometimes, rare, never, therefore each item consists of five points. No statistical tools were used as of other studies. The data collected were analysed.

\section{Ethical approval}

Ethical approval was obtained from the ethical Department of Raja Muthiah Medical College Hospital, Chidambaram.

Table 1: Medication adherence rating scale MARS-5.

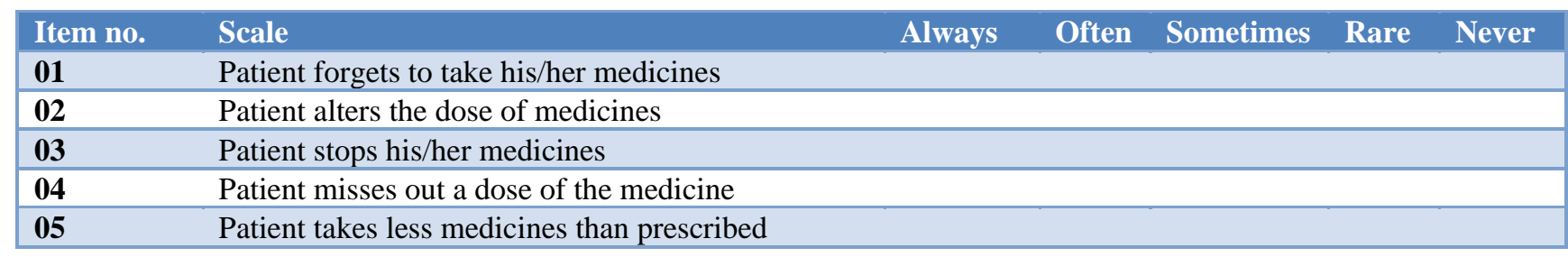

\section{RESULTS}

The study was conducted in patients with major non communicable diseases at the Department of Medicine, $\mathrm{RMMCH}$, Chidambaram, India in order to assess the medication adherence and compare the adherence between the adult and geriatric population. Table 2 shows demographic characteristics in which almost similar number of patients were observed in both the adult (77) and geriatric (73) age groups out of which 88 were males and 62 were females. Out of 150 patients, 29 were literate, 80 were able to read, 41 were unable to read; 132 were married, 18 unmarried; socio-economic habits suggest that 14 were smokers, 13 were alcoholic, 8 had both the habits, majority about 53 were neither smoker nor alcoholic.

Table 3 shows disease and therapy related characteristics were majority were affected with cardiovascular diseases (46.66\%) followed by diabetes mellitus (10\%), stroke (9.33\%), CKD (14.6\%), asthma (6.66\%), hypertension (4\%), COPD $(3.33 \%)$ and others. From among the study population $34.66 \%$ did not have any comorbid conditions while the remaining $65.33 \%$ were suffering with comorbidity. As patients with cardiovascular diseases were more, majority were prescribed with more than 4 or 5 medications which includes mostly antihypertensive, 
antihyperlipidemic, antiplatelets medicines and vitamin supplementation such as BCT.

The frequency of medicine use was mostly twice daily especially for patients with CVD and CVA and thrice for patients with DM. For most of the diseases, patients were asked to visit the outpatient once in a month. Table 4 shows that most of the diseases were associated with hypertension $(26.66 \%)$, some of them with diabetic complications (7.32\%) such as diabetic nephropathy, neuropathy, retinopathy and foot ulcer. Giddiness was a major complaint among the patients especially with CVD. To some proportion anemia's (3.33\%), hypothyroidism $(4.66 \%)$, stroke $(9.33 \%)$ were observed along with other diseases. Medication adherence was assessed using MARS-5.

According to the scale, a score of $<20$ is considered as poor adherence, while 20 to 25 is considered as moderate and a score of 25 is good adherence. Table 5 shows that most of the patients from almost all chronic diseases showed moderate adherence of $60 \%$ (i.e.) MARS-5 score between 20 to 25 , as most of them rarely or sometimes forget the medicine, take less than prescribed or miss a dose or alter the dose of medicine. About $40 \%$ showed poor adherence before patient counselling and was reduced to $13.33 \%$ after patient counselling. Poor adherence was slightly higher in geriatric population $17.80 \%$ than in the adults $9.09 \%$. MARS-5 score was 25 for about $26.66 \%$. Table 7 shows that adherence was more among the adults $(90.90 \%)$ when compared to geriatric population $(82.19 \%)$.

Table 2: Demographic characteristics of study population.

\begin{tabular}{|lll|}
\hline Category & $\begin{array}{l}\text { No. of patients } \\
\mathbf{n = 1 5 0}\end{array}$ & $\begin{array}{l}\text { Percentage } \\
(\%)\end{array}$ \\
\hline Age & 24 & 16 \\
\hline $18-39$ & 53 & 35.33 \\
\hline $40-59$ & 67 & 44.66 \\
\hline $60-80$ & 6 & 4 \\
\hline 80 above & & \\
\hline Gender & 88 & 58.66 \\
\hline Male & 62 & 41.33 \\
\hline Female & & 88 \\
\hline Marital status & 132 & 12 \\
\hline Married & 18 & \\
\hline Unmarried & & 19.33 \\
\hline Education & 29 & 53.33 \\
\hline Literate & 80 & 27.33 \\
\hline Able to read & 41 & \\
\hline Unable to read & & 9.33 \\
\hline Social habits & 14 & 8.66 \\
\hline Smoker & 13 & 5.33 \\
\hline Alcoholic & 8 & 35.33 \\
\hline Both & 53 & \\
\hline None & & \\
\hline
\end{tabular}

Table 3: Disease and therapy related information.

\begin{tabular}{|c|c|c|}
\hline Characteristics & $\begin{array}{l}\text { No. of } \\
\text { patients }\end{array}$ & $\begin{array}{l}\text { Percentage } \\
(\%)\end{array}$ \\
\hline \multicolumn{3}{|l|}{ Diseases } \\
\hline CVD & 70 & 46.66 \\
\hline Stroke & 14 & 9.33 \\
\hline Diabetes mellitus & 15 & 10 \\
\hline Hypertension & 6 & 4 \\
\hline Asthma & 10 & 6.66 \\
\hline COPD & 5 & 3.33 \\
\hline Chronic kidney disease & 22 & 14.66 \\
\hline Cancer & 2 & 1.33 \\
\hline Seizure & 4 & 2.66 \\
\hline Parkinson's disease & 2 & 1.33 \\
\hline \multicolumn{3}{|c|}{ Presence of co-morbidity } \\
\hline Yes & 98 & 65.33 \\
\hline No & 52 & 34.66 \\
\hline \multicolumn{3}{|l|}{ No. of medicines used } \\
\hline One & 16 & 10.66 \\
\hline Two & Nil & Nil \\
\hline Three & 1 & 0.66 \\
\hline Four or five & 19 & 12.66 \\
\hline More than 5 & 114 & 76 \\
\hline \multicolumn{3}{|c|}{ Frequency of medicines used } \\
\hline When needed & 10 & 6.66 \\
\hline Once daily & 26 & 17.33 \\
\hline Twice & 99 & 66 \\
\hline Thrice & 15 & 10 \\
\hline \multicolumn{3}{|c|}{ Frequency of visits to the hospital } \\
\hline When needed & 41 & 27.33 \\
\hline Once in a month & 94 & 62.66 \\
\hline Twice in a month & 15 & 10 \\
\hline
\end{tabular}

Table 4: Co-morbid condition.

\begin{tabular}{|l|l|l|}
\hline Co-morbidity & $\begin{array}{l}\text { No. of } \\
\text { patients }\end{array}$ & $\begin{array}{l}\text { Percentage } \\
(\%)\end{array}$ \\
\hline Dm with nephropathy & 2 & 1.33 \\
\hline Dm with neuropathy & 2 & 1.33 \\
\hline Dm with retinopathy & 4 & 2.66 \\
\hline Dm with foot ulcer & 3 & 2 \\
\hline Dm with hypertension & 38 & 25.33 \\
\hline Pulmonary edema & 3 & 2 \\
\hline Giddiness & 31 & 20.66 \\
\hline $\begin{array}{l}\text { Epitaxis with } \\
\text { hypertension }\end{array}$ & 2 & 1.33 \\
\hline Anaemia & 5 & 3.33 \\
\hline Aspiration pneumonia & 2 & 1.33 \\
\hline Hypothyroidism & 7 & 4.66 \\
\hline Pulmonary TB & 3 & 2 \\
\hline $\begin{array}{l}\text { Drug induced } \\
\text { hypoglycemia }\end{array}$ & 3 & 2 \\
\hline Urinary tract infection & 2 & 1.33 \\
\hline Facial palsy with CVA & 4 & 2.66 \\
\hline Others & 26 & 17.3 \\
\hline
\end{tabular}


Table 5: Medication adherence before and after patient counselling.

\begin{tabular}{|llll|}
\hline $\begin{array}{l}\text { No. of patients } \\
\text { patient based on counselling }\end{array}$ & $\begin{array}{l}\text { Good adherence } \\
\text { MARS-5=25 } \\
\text { N }(\%)\end{array}$ & $\begin{array}{l}\text { Moderate adherence } \\
\text { MARS-5=20 to 25 }\end{array}$ & $\begin{array}{l}\text { Poor adherence } \\
\text { MARS-5=<20 } \\
\text { N }(\%)\end{array}$ \\
\hline Before patient counselling & $15(10)$ & $75(50)$ & $60(40)$ \\
\hline After patient counselling & $40(26.66)$ & $90(60)$ & $20(13.33)$ \\
\hline
\end{tabular}

Table 6: Comparison of medication adherence before patient counselling in adults and geriatrics.

\begin{tabular}{|llll|}
\hline Category & $\begin{array}{l}\text { Good adherence } \\
\text { MARS-5=25 } \\
\text { N }(\%)\end{array}$ & $\begin{array}{l}\text { Moderate adherence } \\
\text { MARS-5=20 to 25 }\end{array}$ & $\begin{array}{l}\text { Poor adherence } \\
\text { MARS-5=<20 } \\
\text { N }(\%)\end{array}$ \\
\hline Adult (77) & $10(12.98)$ & $44(57.14)$ & $23(29.87)$ \\
\hline Geriatric $\mathbf{( 7 3 )}$ & $5(6.84)$ & $31(42.46)$ & $37(50.68)$ \\
\hline
\end{tabular}

Table 7: Comparison of medication adherence after patient counselling in adults and geriatrics.

\begin{tabular}{|llll|}
\hline Category & $\begin{array}{l}\text { Good adherence } \\
\text { MARS-5=25 } \\
\text { N }(\%)\end{array}$ & $\begin{array}{l}\text { Moderate adherence } \\
\text { MARS-5=20 to 25 }\end{array}$ & $\begin{array}{l}\text { Poor adherence } \\
\text { MARS-5=<20 } \\
\text { N }(\%)\end{array}$ \\
\hline Adults (77) & $22(28.57)$ & $48(62.33)$ & $7(9.09)$ \\
\hline Geriatric $\mathbf{( 7 3 )}$ & $18(24.65)$ & $42(57.53)$ & $13(17.80)$ \\
\hline
\end{tabular}

\section{DISCUSSION}

Medication adherence in chronic illness is substantial without which the rates of mortality and morbidity would become worse, also leading to increased hospital readmissions and adverse effects. It not only affects the clinical outcome but also the financial outcome of the healthcare system. ${ }^{4}$

So, providing pharmaceutical care through patient counseling would be supportive in the healthcare system and also plays an immense role in reducing nonadherence among the patients. ${ }^{7}$

The study observed that some of the demographic, disease and therapy related characteristics of the patient population also affect adherence in various ways. ${ }^{4}$ Advancing age affects adherence by increase in chance of forgetfulness, lack of assistance and polypharmacy which is supported by a study conducted in Pakistan. This study did not find any obvious association between gender and adherence. Majority of the subjects were illiterate as the study was conducted in rural area but some of them were slightly able to read and understand.

Disease type and comorbidity also plays major role in adherence to medicine. Adherence in cardiovascular patients was $50 \%$ according to a study conducted in Pakistan and in one more study conducted in Australia, adherence was $43 \%$ for asthma, and in one more study adherence was $57 \%$ for hypertension, concluding that adherence varies with the type of disease. ${ }^{8-10}$

Number of medicines used also has an effect on medication adherence as some of the patients get so annoyed to take more medicines therefore considering, polypharmacy also indirectly affects adherence. ${ }^{4}$

This study shows that before patient counselling, chronic disease population mostly has poor adherence and was improved after proper patient counselling which is supported by two other studies. Also, patient counseling through telephone calling and OP visits using pictogram and educating them on the importance of drug use proved to improve adherence. ${ }^{11}$ The current study did not record income details, adverse effects of the drug or duration of treatment like other studies.

\section{CONCLUSION}

Based on our study we conclude that through pharmaceutical care, patient counseling would convey the actual importance of medicine in chronic illness and could improve the adherence to medicine, thereby reducing further complications of the disease through long-term hospital stay or re-admissions.

Funding: No funding sources

Conflict of interest: None declared

Ethical approval: The study was approved by the Institutional Ethics Committee

\section{REFERENCES}

1. Roy N, Sajith M, Bansode M. Assessment of Factors Associated with Low Adherence to Pharmacotherapy in Elderly Patients. J Young Pharmacists. 2017;9(2):272-6.

2. Improving Prescription Medicine Adherence is key to better Health Care. PhRMA. 2011:1-8. Phrma- 
docs.phrma.org. 2020. Available at: http://phrmadocs.phrma.org/sites/default/files/pdf/PhRMA_Impro ving\%20Medication\%20Adherence_Issue $\%$.

Accessed on 7 August 2020.

3. CPD 40: Medication Adherence in Chronic Disease. Pharmacynewsireland.com. 2020. [cited 7 August 2020] Available <https://pharmacynewsireland.com/wpcontent/uploads/2015/10/IPN-CPD-40.pdf>.

4. Shaheen N, Haq N, Riaz S, Naseem A, Zarak M. Assessment of Medication Adherence among Noncommunicable Chronic Disease Patients in Quetta, Pakistan: Predictors of Medication Adherence. Asian J Med Health. 2017;4(4):1-9.

5. Rosen O, Fridman R, Rosen B, Shane R, Pevnick J. Medication adherence as a predictor of 30-day hospital readmissions. Patient Prefer Adherence. 2017;11:801-10.

6. Alfian SD, Annisa N, Fajriansyah F. Modifiable Factors Associated with Non-adherence to Antihypertensive or Antihyperlipidemic Drugs Are Dissimilar: A Multicenter Study Among Patients with Diabetes in Indonesia. J Gen Intern Med. 2020.

7. Carollo A, Adamo A, Giorgio DC, Polidori P. DGI069 the Importance of Clinical Pharmacist
Counselling in Improving Patient Medication Adherence. European J Hospital Pharmacy. 2013;20(1):A121.1-A121.

8. Kronish I, Ye S. Adherence to Cardiovascular Medications: Lessons Learned and Future Directions. Progress Cardiovascular Dis. 2013;55(6):590-600.

9. Reid D, Abramson M, Raven J, Walters H. Management and treatment perceptions among young adults with asthma in Melbourne: The Australian experience from the European Community Respiratory Health Survey. Respirology. 2000;5(3):281-7.

10. Almas A, Hameed A, Ahmed B, Islam M. Compliance to antihypertensive therapy. J Coll Physicians Surg Pak. 2006;16(1):23-6.

11. Syed L, Lynn M. Medication and non-adherence in the older adult. Medicine Health Rhode Island. 2009;92(12):418-9.

Cite this article as: Andavar M, Natarajan M, Selvam MP. Assessment of medication adherence using medication adherence rating scale-5 in patients with major non-communicable diseases at tertiary care hospital. Int J Basic Clin Pharmacol 2020;9:1412-6. 